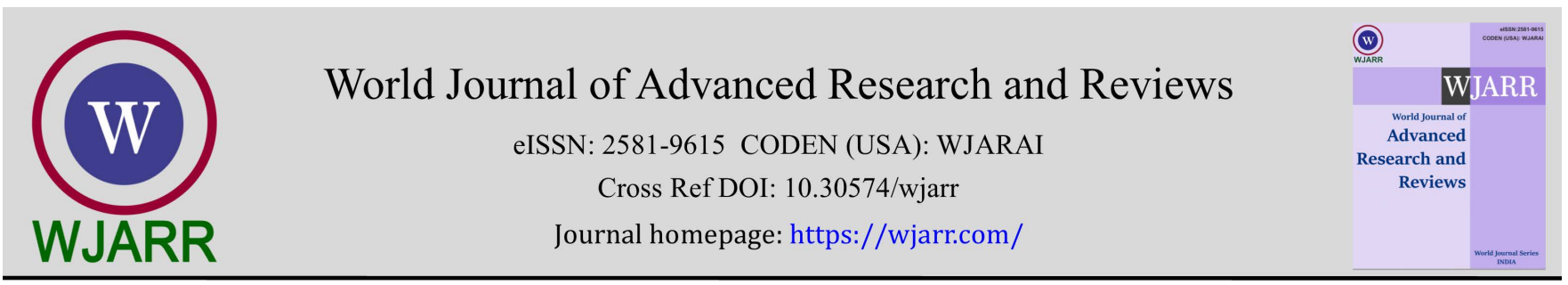

(RESEARCH ARTICLE)

Check for updates

\title{
Weight's influence at the exercise's impact on breast cancer risk
}

Vouxinou Andriani ${ }^{1}$, Iatrakis Georgios ${ }^{1}$, Zervoudis Stefanos ${ }^{2}$, Dagla Maria ${ }^{1}$, Orovou Eirini ${ }^{1}$, Palaska Ermioni 1, Sarella Angeliki ${ }^{1}$, Iliadou Maria ${ }^{1}$, Bothou Anastasia ${ }^{3}$ and Antoniou Evangelia 1,*

${ }^{1}$ Department of Midwifery, University of West Attica, Athens, Greece.

2 University of Montpellier, Breast Department, Rea Hospital, Athens, Greece.

${ }^{3}$ Department of Obstetrics and Gynecology, Democritus University of Thrace, Komotini, Greece.

World Journal of Advanced Research and Reviews, 2021, 12(03), 057-060

Publication history: Received on 07 October 2021; revised on 29 November 2021; accepted on 01 December 2021

Article DOI: https://doi.org/10.30574/wjarr.2021.12.3.0654

\begin{abstract}
Obesity and exercising affect the risk for breast cancer in an opposite direction. From recent data, it was found that training during night hours can mitigate the beneficial effects of exercise on that risk. In the present study, it was examined the simultaneous effect of daytime or nighttime exercise and woman's weight on the risk of breast cancer. It was concluded that the impact of nighttime exercise on breast cancer risk was marginally influenced by woman's weight. The aim of the study was to examine the simultaneous effect of daytime or nighttime exercise and woman's weight on the risk of breast cancer. A retrospective analysis of ninety-two women with or without a history of breast cancer, examining concurrently the influence of daytime or nighttime exercise and weight on breast cancer risk. In the simultaneous assessment of woman's weight and exercise on breast cancer risk, it was found that the effect of the nighttime exercise remained strong, despite an increase in the confidence interval of the associated risk. The impact of nighttime exercise on breast cancer risk was marginally affected from the woman's weight.
\end{abstract}

Keywords: Breast; Cancer; Exercise; Weight

\section{Introduction}

Excess adiposity and inactivity increase both breast cancer risk and poor outcomes in individuals diagnosed with breast cancer [1]. Actually, obesity in postmenopausal women is included in the major factors that has been consistently associated with a higher risk of breast cancer from both European [2] and US [3] data. On the contrary, postmenopausal women who lose weight have lower breast cancer risk than those with stable weight [4]. Furthermore, exercise seems to protect from breast cancer [5]. This protection is likely mediated through weight control and hormonal influences such as impairing serum insulin levels and reducing sex hormones [6, 7]. When exercising, metabolism increases and blood parameters seem to be affected $[8,9]$. The endocrine system seems to play an important role in those changes [10]. In a recent publication, we confirmed the beneficial effect of exercise in breast cancer risk. However, it was also found that the previous protection seems to be mitigated with exercising exclusively in nighttime hours [11].

\section{Aim}

The aim of the present study was to investigate the possible effect of women's weight in the influence of exercise on breast cancer risk examining simultaneously the related variables.

\footnotetext{
${ }^{*}$ Corresponding author: Antoniou Evangelia

Department of Midwifery, University of West Attica, Athens, Greece.

Copyright $(2021$ Author(s) retain the copyright of this article. This article is published under the terms of the Creative Commons Attribution Liscense 4.0.
} 


\section{Material and methods}

\subsection{Data Source}

The material was taken from a PhD thesis at the Department of Midwifery, University of West Attica, in the final exploratory phase of identifying relationships between different data variables. The data were collected from relevant questionnaires filled in at a big private hospital (Rea Hospital), and adjusted Google Forms (total number: 300) for a predetermined time period (November 2019 to May 2020), ensuring anonymity.

\subsection{Approval}

Data collection followed a relevant permit of the competent research ethics and scientific committees of the above unit (date: 15.11.2019)

\subsection{Statistical Methods}

IBM Statistical Package for the Social Sciences (SPSS) 26.0 was used for the analysis in a univariate and multivariate manner. The above thesis, inter alia, examined weight's influence at the exercise's impact on breast cancer risk. From ninety-two women with a history of exercising, 40 women without a history of breast cancer exclusively exercised during the day, 15 women with a history of breast cancer exclusively exercised during the day, 17 women without a history of breast cancer exclusively exercised during the night and 20 women with a history of breast cancer exclusively exercised during the night. Body mass index (BMI) was used to categorize women in an overweight-obese or normal category. BMI was calculated from women's weight and height using the formula: [weight (kg)/height $(\mathrm{m})^{2}$ ]. Women with a BMI of 18.5 to $24.9 \mathrm{~kg} / \mathrm{m}^{2}$, were classified as normal, and women with a BMI of $\geq 25 \mathrm{~kg} / \mathrm{m}^{2}$ as overweight-obese (no woman had a BMI $<18.5 \mathrm{~kg} / \mathrm{m}^{2}$ ). The influence of night-time exercise and weight on the risk of breast cancer was first estimated in a univariate analysis (first paragraph of the Results and Table 1). Subsequently, in a multivariate analysis, it was estimated the impact of weight and exercise characteristic (daytime or nighttime training), including women's age (see Table 2).

\section{Results}

The statistical analysis of the sample showed that the odds ratio-for no protection from breast cancer was almost three times higher (odds ratio $>3$ with a confidence nterval $>1$ to $>7.5$ and $p<0.05$ ) in women exercising during nighttime hours compared with women exercising during daytime hours. However, this result seemed to mainly derive from the higher number of the healthy women without a history of breast cancer exercising during non-night hours compared to the ones with a history of breast cancer exercising during non-night hours and not exclusively from the comparison of relevant data during night hours per se.

Increased weight seemed to increase the risk of breast cancer (almost twice), not taking into account the other parameters of the material. However, the confidence interval included one (0.7-4.1) and, of course, the p was not $<0.05$ (0.20) (Table 1).

Table 1 Effect of weight on the risk of breast cancer in women included in the study

Weight as the only variable in the equation

\begin{tabular}{|l|c|c|c|}
\hline \multirow{2}{*}{ Sig. } & \multirow{2}{*}{$\operatorname{Exp(B)}$} & L5\% C.I.* for EXP(B) \\
\cline { 3 - 4 } & Lower & Upper \\
\hline 0.202 & 1.747 & 0.741 & 4.119 \\
\hline \multicolumn{3}{|c}{} \\
*C.I.: Confidence Interval
\end{tabular}

Furthermore, during the simultaneous assessment of the factors examined (time of day during which the exercise was performed, age and weight), it was found that the effect of the time at which the exercise was performed on the risk of breast cancer, remained strong with $\mathrm{p}<0.05$. Thus, despite the increase in the confidence interval of the associated risk, this again did not include one (Table 2), as was found when examining the effect of only the Time at which Exercise was Performed (TEP) on that risk and when examining the co-effect of the TEP and the age of the participants. Consequently, although there was a marginal influence (non- statistically significant) of the weight on the results, the main conclusion of the study (see below) was not affected by an uneven distribution of overweight-obese women in night sports. 
Table 2 Multifactorial effect on the risk of breast cancer, including the time (day or night) of exercise, age and weight of women

Variables in the Equation

\begin{tabular}{|l|l|c|c|c|}
\hline & & & \multicolumn{2}{|c|}{$\mathbf{9 5 \%}$ C.I. for $\operatorname{Exp(B)}$} \\
\cline { 4 - 5 } & Sig. & $\operatorname{Exp(B)}$ & Lower & Higher \\
\hline Time (day or night) & 0,023 & 3,627 & 1,191 & 11,050 \\
\hline Age & 0,397 & 0,654 & 0,245 & 1,747 \\
\hline Weight & 0,737 & 0,826 & 0,270 & 2,524 \\
\hline
\end{tabular}

\section{Discussion}

Hard data synthesize evidence on the biological mechanisms underlying obesity-breast cancer links [12]. Similarly, obesity and dysregulated metabolism in night-shift workers [13] could increase breast cancer risk [14]. As "a general statement", obesity and exercising are included in a big group of factors that can affect the risk for breast cancer in an opposite direction [15]. In brief, exercise defending obesity [16] could protect from breast cancer. It seems that several endocrinological factors, through exercise, could influence breast risk including melatonin, estrogen levels and perhaps specific estrogens [17].

In a recent publication, we found that the protection of exercise on breast cancer risk is probably mitigated with exercising exclusively in nighttime hours [11]. However, an accumulation of obese women with breast cancer in the group of women exercising during nighttime hours could impair the previous conclusion. The results of the present study excluded this hypothesis. Although the inclusion of weight in the examined parameters increased the confidence interval of odds ratio result related to exercise, the night-time training still marginally reduced the "general" protection of exercise on breast cancer. However, given that only few women have included a systematic exercising regimen in their daily activities, it must be emphasized that even the mildest type of exercise seems to be protective for breast cancer [18], preferably during daytime hours [11].

This analysis further confirmed that the protective impact of exercising on breast cancer was mitigated (regarding its primary occurrence) when the exercise was performed exclusively during night hours.

\section{Conclusion}

The protective impact of exercising on breast cancer was possibly mitigated when exclusively exercising during the night, an effect that was only marginally affected from woman's weight.

\section{Compliance with ethical standards}

\section{Disclosure of conflict of interest}

We have no conflict of interest to declare.

\section{Statement of informed consent}

Informed consent was obtained from all individual participants included in the study.

\section{References}

[1] Ligibel JA, Basen-Engquist K, Bea JW. Weight Management and Physical Activity for Breast Cancer Prevention and Control. Am Soc Clin Oncol Educ Book. 2019; 39: e22-e33.

[2] Lahmann PH, Hoffmann K, Allen N, van Gils CH, Khaw KT, Tehard B, et al. Body size and breast cancer risk: findings from the European Prospective Investigation into Cancer and Nutrition (EPIC).Int J Cancer. 2004; 111: $762-71$. 
[3] Morimoto LM, White E, Chen Z, Chlebowski RT, Hays J, Kuller L, et al. Obesity, body size, and risk of postmenopausal breast cancer: the Women's Health Initiative (United States) Cancer Causes Control. 2002; 13(8): 741-751.

[4] Chlebowski RT, Luo J, Anderson GL, Barrington W, Reding K, Simon MS, et al. Weight loss and breast cancer incidence in postmenopausal women.Cancer. 2019; 125: 205-12.

[5] Chlebowski RT. Factors that modify breast cancer risk in women. UpToDate. 2020.

[6] Ligibel JA, Campbell N, Partridge A, Chen WY, Salinardi T, Chen H, et al. Impact of a mixed strength and endurance exercise intervention on insulin levels in breast cancer survivors. J Clin Oncol. 2008; 26: 907-12.

[7] de Boer MC, Wörner EA, Verlaan D, van Leeuwen PAM.The Mechanisms and Effects of Physical Activity on Breast Cancer. Clin Breast Cancer. 2017; 17: 272-8.

[8] Gronesova P, Cholujova D, Kozic K, Korbuly M, Vlcek M, Penesova A, Imrich R, Sedlak J, Hunakova L. Effects of short-term Pilates exercise on selected blood parameters. Gen Physiol Biophys. 2018; 37: 443-51.

[9] Hargreaves M, Spriet LL. Exercise Metabolism: Fuels for the Fire. Cold Spring HarbPerspect Med. 2018; 8: a029744.

[10] Hackney AC, Lane AR. Exercise and the Regulation of Endocrine Hormones. Prog Mol Biol Transl Sci. 2015; 135 : 293-311.

[11] Vouxinou A, Iatrakis G, Zervoudis S, Dagla M, Orovou E, Palaska E, Sarella A, Antoniou E.The Impact of the Characteristics of Exercise on The Risk of Breast Cancer.Mater Sociomed. 2021; 33: 195-8.

[12] Bustamante-Marin XM, Merlino JL, Devericks E, Carson MS, Hursting SD, Stewart DA. Mechanistic Targets and Nutritionally Relevant Intervention Strategies to Break Obesity-Breast Cancer Links. Front Endocrinol (Lausanne). 2021; 12: 632284.

[13] Nelson RJ, Chbeir S. Dark matters: effects of light at night on metabolism. Proc Nutr Soc. 2018; 77: 223-9.

[14] Wang F, Yeung KL, Chan WC, Kwok CC, Leung SL, Wu C, Chan EY, Yu IT, Yang XR, Tse LA. A meta-analysis on doseresponse relationship between night shift work and the risk of breast cancer. Ann Oncol. 2013; 24: 2724.

[15] Iatrakis G. Breast Cancer. In: Gynecologic Oncology-ISBN: 978-618-83912-2-2. Athens, “Desmos Digital IKE”. 735740 .

[16] Fock KM, Khoo J. Diet and exercise in management of obesity and overweight.J Gastroenterol Hepatol. 2013; 28(4): 59-63.

[17] Razzak ZA, Khan AA, Farooqui SI. Effect of aerobic and anaerobic exercise on estrogen level, fat mass, and muscle mass among postmenopausal osteoporotic females. Int J Health Sci (Qassim). 2019; 13: 10-6.

[18] Kraschnewski JL, Schmitz KH. Exercise in the Prevention and Treatment of Breast Cancer: What Clinicians Need to Tell Their Patients? Review Curr Sports Med Rep. 2017; 16: 263-7. 